\title{
The Role of Routines in Reducing Pervasive Uncertainty
}

\author{
Becker, Markus C.; Knudsen, Thorbjørn
}

Document Version

Final published version

Publication date:

2001

\section{License \\ CC BY-NC-ND}

Citation for published version (APA):

Becker, M. C., \& Knudsen, T. (2001). The Role of Routines in Reducing Pervasive Uncertainty. The Link

Program. LINK Working Paper No. 2001-28

Link to publication in CBS Research Portal

\section{General rights}

Copyright and moral rights for the publications made accessible in the public portal are retained by the authors and/or other copyright owners and it is a condition of accessing publications that users recognise and abide by the legal requirements associated with these rights.

\section{Take down policy}

If you believe that this document breaches copyright please contact us (research.lib@cbs.dk) providing details, and we will remove access to the work immediately and investigate your claim. 
THE ROLE OF ROUTINES IN REDUCING PERVASIVE UNCERTAINTY

\author{
Markus C. Becker \\ Department of Marketing \\ University of Southern Denmark \\ DK-5230 Odense M \\ Denmark \\ Tel. +45-65503350 \\ Fax +45-66155129 \\ mab@sam.sdu.dk \\ Thorbjørn Knudsen \\ Department of Marketing \\ University of Southern Denmark \\ DK-5230 Odense M \\ Denmark \\ Tel. +45-65503148 \\ Fax +45-66155129 \\ tok@sam.sdu.dk
}

Draft of 20/09/01

\title{
Acknowledgements
}

The authors would like to thank Zur Shapira, Peter Zemsky, Kent Miller and other participants at the 2001 Academy of Management session on Risk, Decision Making, and Strategy for useful comments. We also thank the participants of the 2001 EGOS meetings for helpful suggestions. Any remaining error was produced without any help. 


\begin{abstract}
Under conditions of pervasive uncertainty, increasing the "amount" of information will not necessarily decrease uncertainty. Perhaps more information will even increase uncertainty. Since information may be valuable, even under conditions of pervasive uncertainty, this amounts to a puzzle. Its solution seems to hold the promise of understanding how decisionmakers actually go about reducing uncertainty in its more pervasive forms and is therefore at the center of attention in the present article. It is hypothesized that the role of routines in decision-making provides the key to solve the "information puzzle." Drawing on data from 56 companies, the argument is supported by empirical tests employing path analysis by linear structural equations modeling.
\end{abstract}

Key words: routines, uncertainty, Knightean uncertainty, information, decision-making; empirical research

JEL classifications: D81, D83, M10 


\section{THE ROLE OF ROUTINES IN REDUCING PERVASIVE UNCERTAINTY}

Choice under uncertainty is one of the central problems in managerial and economic theories of choice. According to standard approaches in economics, the problem of choice under uncertainty may essentially be remedied by increasing the amount of information available to the decision-maker (Luce \& Raiffa, 1957). A large class of choice problems however seems immune to this strategy, as casual observation, experimental economics (Kagel \& Roth, 1995), various heterodox economists (Hodgson, 1988; Loasby, 1999) and the management literature point out (Weick, 1995). A common theme in these otherwise unrelated streams of literature is that there may be situations in which uncertainty prevails despite increases in information. We use the terms Knightean and pervasive uncertainty synonymously throughout the paper to denote such situations. As explained below, Knightean uncertainty is a situation in which it is impossible to associate point probabilities with events.

From a theoretical perspective, the choice problems that are immune to solution by merely increasing the amount of information can be characterized by an absence of mathematical structure. This situation, whatever its cause, is often referred to as Knightean uncertainty (Knight, 1921; Runde, 1998). Under conditions of Knightean uncertainty, as opposed to risk, an increase in information is not likely to be helpful. As Weick suggests, more information may even increase uncertainty (Weick, 1995). If decision makers are seen to have limited cognitive resources (Simon, 1955), then the more attention decision-makers devote to solve impossible choice situations, the less will be available to take care of those problems that can be solved and uncertainty will increase. How then may decision-makers go about reducing pervasive uncertainty? Obviously, if information increases uncertainty, there should be less of it. This may not be a very good strategy however. After all, information may be valuable even under conditions of pervasive uncertainty. As we see it, this amounts to a puzzle, and a somewhat overlooked puzzle at that (one notable exception is Simon, 1947). 
This is rather curious since its solution seems to hold the promise of understanding how decision-makers are capable of dealing with and/ or reducing uncertainty in its more pervasive forms.

In what follows the "information puzzle" is at the center of attention, i.e., should information be increased or decreased in the face of pervasive uncertainty? As indicated by previous authors (e.g. Nelson and Winter, 1982; Richardson, 1960), considering "routines" may hold the key to solving the information puzzle. The present paper therefore aims to formulate and test a descriptive model that indicates how routines allow managers to successfully cope with pervasive uncertainty.

The paper proceeds as follows. The ensuing section provides a brief review of the most widely used conceptualizations of uncertainty. Section three develops testable hypotheses, section four introduces data and measures and section five presents the results. The findings are discussed in section six followed by the conclusion.

\section{LITERATURE REVIEW: CONCEPTUALIZATIONS OF UNCERTAINTY}

In order to consider the role of information in reducing uncertainty, this section briefly reviews the central conceptualizations of uncertainty in theories of choice. In economics, uncertainty arises when a decision can lead to more than one possible consequence (Radner, 1994: 728). Uncertainty thus frustrates intentional choice. The standard conceptualization of uncertainty is usually based on Luce and Raiffa's (1957) tripartite classification, which differentiates the realm of decision-making under certainty, risk, and uncertainty. Risk and uncertainty are distinguished by the nature of probabilities assigned to the different possible outcomes. The situation is typically envisioned in terms of a subset of alternatives, a corresponding set of consequences and an index function which reflects the decision-maker's utility for the consequence associated with alternative $X$ when nature is in state $Y$. The 
decision-making problem, then, consists of choosing the subset of alternatives associated with optimal expected utility.

In the realm of certainty there is no real problem since specific outcomes are secured per definition. In the realm of risk, the probabilities of outcomes are assumed known. The decision-maker can, therefore, proceed by computing the expected utility of the alternatives and choose those with the largest value. In the case of uncertainty the problem is more challenging. To be precise, the challenge in the case of uncertainty is to deduce the existence of a function whose expected value controls choice, a problem solved by von Neumann and Morgenstern (Savage, 1954). Given the existence of such a function, the decision-maker can generate a subjective probability distribution for outcomes by using statistical information to update or generate an a priori distribution (Savage, 1954; Luce \& Raiffa, 1957). Thus, objective probabilities are associated with risk whereas subjective probabilities are associated with uncertainty. In the realm of risk, all the possible consequences and the likelihood (probability) of each consequence are known, while in a situation of uncertainty, there is a set of possible specific outcomes, but the likelihood (or probability) of each outcome is initially unknown (Savage, 1954). The trick then is to use information to deduce a well-behaved index function, one whose expected values control choice.

As opposed to this conceptualization of uncertainty, some authors argue that also a much stronger, pervasive form of uncertainty must be considered. In the words of March and Simon, "decision-making under uncertainty does not even allow complete knowledge of all possible outcomes and their associated probabilities and payoffs" (March \& Simon, 1958: 137). This notion of pervasive uncertainty goes back at least to Knight and Keynes. For Knight, a situation of risk is characterized by measurable uncertainty (a situation in which the probabilities of the outcomes are not known objectively, but can be estimated subjectively). Knight's point is that this situation however "is so far different from an unmeasurable one that it is not in effect an uncertainty at all" (Knight, 1921: 20). This pervasive form of 
uncertainty characterized by the impossibility of computing point probabilities has become known as "Knightean uncertainty." Also for Keynes, uncertainty corresponded to an absence of measurable probabilistic knowledge: "About these matters there is no scientific basis on which to form any calculable probability whatever. We simply do not know" (Keynes, 1973: 114).

The implications of this are as follows: First, let us acknowledge the existence of pervasive uncertainty in which the situation is so ill structured that the possible outcomes will remain unknown despite any attempt to remedy the situation. Let us, perhaps slightly incorrectly, refer to this as Knightean uncertainty. Note that our use of the term Knightean uncertainty is consistent with but broader than Knight's (1921) original definition of uncertainty as one specific instance in which there is no support for an index function whose expected value controls choice (Runde, 1998).

Second, situations characterized by Knightean uncertainty may call for different strategies than those situations, which, in some sense, may be remedied by increasing the amount of available information.

Rational choice theory treats the problem of choice under uncertainty within the utilitymaximizing approach. By assumption, uncertainty may be reduced by sufficient statistical information. This translates into a general strategy of information seeking in which the basis for estimation of subjective probabilities and their accuracy will improve as the amount of available information increases. In the absence of Knightean uncertainty, the general strategy to improve choice under uncertainty is therefore to increase the amount of information. As explained in the ensuing section, introducing Knightean uncertainty may lead to the opposite conclusion. 


\section{HYPOTHESES}

In the following, we use our previous clarification of forms of uncertainty to develop hypotheses about the relation between intelligence dissemination, uncertainty and routinization. We argue that in an information extensive world (a world with an abundance of information), increasing intelligence dissemination will also increase uncertainty - see the section on "Intelligence dissemination and uncertainty," below. The problem may be described as creating a viable basis for selective attention. Since routinization may create such a basis, we argue (in the section "Routinization and uncertainty") that increasing routinization will reduce uncertainty. That is, routinization can be seen as a defense against the adverse effects of intelligence dissemination in an information extensive world. Therefore, we hypothesize (in the section "Intelligence dissemination and routinization") that increasing intelligence dissemination will also increase routinization. In terms of derived effects, we argue (in the section "Routinization and responsiveness") that increasing routinization will lead to an increase in responsiveness and (in "Detecting changes and responsiveness") that increasing the speed of detecting changes, in turn, will increase responsiveness. According to our argument (in "Intelligence dissemination, uncertainty and the detection of changes") the hypothesized first-order effect of intelligence dissemination is that it allows faster detection of changes. Intelligence dissemination may however, as a second-order effect, mediate the reduction of uncertainty through routinization. The conceptual model guiding the empirical test encompasses all these effects and is shown in Figure 1 below. The theoretical underpinning of this model is provided below.

Figure 1 


\section{Intelligence dissemination and uncertainty}

The previous section defined three concepts associated with choice under uncertainty: "risk" (the possible outcomes and their probabilities are known), "uncertainty" (the possible outcomes are in principle known but their probabilities can only be subjectively estimated), and "Knightean uncertainty" (neither the possible outcomes nor their probabilities are known). Due to the difference between these forms of uncertainty, we believe that different strategies are appropriate to deal with their presence. As explained above, risk and uncertainty can be resolved by gathering more information.

In the management literature, Knightean uncertainty is often described by its implications, typically in terms of some sort of ambiguity. According to this literature, ambiguity, and thus situations of Knightean uncertainty, cannot be resolved by gathering more information (Weick, 1995). The reason for this is that a situation characterized by Knightean uncertainty has too little structure for information to be helpful. As a basis for a realistic theory of choice, we further assume "bounded rationality," according to which cognitive resources viewed in relation to a specific environment are limited (Simon, 1947, 1955; March, 1978). It is this additional assumption which makes the strategy of increasing information in the face of Knightean uncertainty questionable.

By definition, Knightean uncertainty implies that it is impossible to assign probabilities to outcomes. In theoretical terms this describes a situation where a unique mapping of alternative to outcomes cannot be defined. Therefore, to increase the amount of information will not have the slightest effect in reducing Knightean uncertainty. The underlying empirical reasons for such situations include confounding of multiple causes, interference of third variables, and the appearance of novel elements in the choice set.

Increasing the amount of information will not decrease Knightean uncertainty, but neither can it be made worse. Due to the decision maker's limited cognitive resources implied by our assumption of "bounded rationality," there is a negative indirect effect. Allocating 
scarce information processing resources to a problem that is impossible to solve because it is characterized by Knightean uncertainty, will further reduce the cognitive resources available to deal with other problems. And when there is less attention and information allocated to deal with problems that can be solved, the general state of uncertainty will increase. Therefore, if a decision maker faces multiple problems, an increase of information to solve one problem characterized by Knightean uncertainty may well increase the general state of uncertainty.

Returning to our discussion of uncertainty, we distinguish between situations in which more information, in principle, is helpful (uncertainty and risk) and those situations in which increasing the amount of information is unhelpful (Knightean uncertainty). Adding the snag of information extensiveness, we believe that few real-life situations escape the conclusion that increasing the amount of information will increase uncertainty on part of a boundedly rational decision-maker. In all those situations characterized by Knightean uncertainty, more information will, by definition, not help and may well increase the general state of uncertainty. Therefore, we hypothesize that increasing information will lead to an increase in uncertainty in the presence of pervasive uncertainty and/ or information extensiveness.

Hypothesis 1. In the presence of pervasive uncertainty and/ or information extensiveness, increasing intelligence dissemination leads to an increase in uncertainty.

\section{Routinization and uncertainty}

In the previous section, we have stated that the strategy most often applied in reducing uncertainty might not work under conditions of Knightean uncertainty. Does this mean there is an insurmountable problem for decision-makers? If not, how can decision-makers deal with the problem? The economics, institutional economics and organization theory literatures contain hints regarding a possible "strategy" for dealing with pervasive uncertainty (see e.g. Heiner, 1983; Perrow 1970; Shapiro \& Varian, 1999). A very clear statement is Heiner's (1983: 570) hypothesis that, "greater uncertainty will cause rule-governed behavior to exhibit 
increasingly predictable regularities, so that uncertainty becomes the basic source of predictable behavior."

Although Heiner's statement implies a causal direction that runs counter to what is required for a strategy, it is a strong basis for hypothesizing a connection between routinization and reducing uncertainty. It is not the only such basis, though. Arguments can be found which turn the direction of causality so increases in routinization may be viewed as an uncertainty decreasing strategy (see e.g. Hodgson, 1988; Richardson, 1960; Shapiro \& Varian, 1999). Thus, firms may (1) increase predictability by fixing certain parameters, and they may, at the same time, (2) free limited cognitive resources. Institutions and routines not only work as constraints but also, as emphasized by Hodgson (1988), are sources of regular and predictable behavior in the face of uncertainty, complexity and information overload. North (1990) provides a similar statement. According to North (1990), uncertainty stems from the agents' computational limitations and the complexity of the environment. In consequence of these cognitive limitations, in conjunction with the uncertainties involved in deciphering the environment, North $(1990,25)$ argues, "rules and procedures evolve to simplify the process." Thus predictability may increase due to the presence of institutions, which exist prior to the firm's entry in a particular society or industry. Firms may also choose to introduce routines to the same effect.

The classical statement of this strategy is Knight's (1921) suggestion that firms may prefer relatively predictable lines of activity to more speculative operations. Later, Knight \& Merriam (1948) suggested that predictability increases in the tendency to follow routines. Richardson's (1960) suggestion that "restraints" introduce the necessary friction for the working of the economic system further elaborates on this issue. Whatever the source of such "restraints," Richardson $(1960,69)$ suggests they serve to “...increase the supply of market information by reducing the freedom of action of individual units in the system." Since the strength of these "restraints" may, within limits, be viewed as endogenous variables, 
Richardson (1960) opens the possibility that routinization, too, may be viewed as an uncertainty decreasing strategy.

More recently, the managerial literature has emphasized that routinization reduces systems level uncertainty associated with competition and technological risk (Shapiro \& Varian, 1999). The firm may, for example, choose to routinize their operations in order to deliver standardized products that may increase the acceptance of new technologies (Ibid.). Apart from introducing predictability at the systems level, a number of authors (e.g. Simon, 1947) have emphasized that routines also greatly reduce the individual level cognitive demands. Routines allow managers to cope with uncertainty under the constraint of bounded rationality because they can be used to save on mental efforts and thus preserve scarce capacity required to deal with non-routine events (Egidi \& Ricottilli, 1997). For the two reasons provided here (routines introduce predictability by fixing certain parameters and routines free cognitive resources), we hypothesize the following relationship between routinization and uncertainty:

Hypothesis 2. Increasing routinization will decrease uncertainty.

\section{Intelligence dissemination and routinization}

We have argued that in an information extensive world, intelligence dissemination leads to an increase in uncertainty and, at the same time, that routinization may decrease uncertainty. What, however, does this mean for the relation between intelligence dissemination and routinization?

From the assumption of bounded rationality and limited cognitive resources (Simon, 1955), it follows that there will be a threshold of information extensiveness surpassing the limit of the actor's cognitive resources. There will be a point at which her cognitive resources will be overburdened and countermeasures will have to be used in order to cope with the situation. Moreover, in the case of an ill-structured environment, it may simply be impossible 
to derive a function that can support the ordering of outcomes. In both instances, a countermeasure has to be designed, which will simplify and/ or structure the decision problem so it can be handled within the cognitive limitations of the individual decision-maker.

As the previous section indicates, routinization provides one general form of the solution to this problem. Routines greatly reduce the cognitive demands on individuals and thus preserve scarce information-processing and decision-making capacity (Egidi \& Ricottilli, 1997). When the organization increases its level of intelligence dissemination (information flow), it is, therefore, suggested that the organization must increasingly rely on routinized procedures.

Note that routinization is not the only strategy to deal with increased intelligence dissemination. Specialization is a further general strategy that may be used to handle increasing levels of intelligence dissemination. Thus, a business organization may channel different types of information to different departments, and so on. It is important to recognize that such specialization in intelligence dissemination must necessarily rely on some sorting procedure. Again, in the case of information extensiveness, this sorting procedure must itself be based on a routinized treatment of the channeling of information. Although increased specialization may well be used as a countermeasure to handle increases in the level of intelligence dissemination, this solution will always go hand in hand with increased routinization. According to a classic argument, specialization has the further possible detrimental effect that it leads to an increase in the need for coordination, a problem that may be countered by increased routinization (Nelson \& Winter, 1982; Loasby, 1999). Due to the direct effect, that routines greatly reduce the cognitive demands on individuals, and because of the indirect effect associated with specialization, we suggest:

\footnotetext{
Hypothesis 3. Increasing intelligence dissemination leads to an increase in routinization.
} 


\section{Routinization and responsiveness}

By now, we have argued that in an information extensive world, intelligence dissemination entails two effects: on the one hand an increase in uncertainty and on the other an increase in routinization that, in turn, may reduce uncertainty. This leads to an unclear outcome that must be treated as an empirical question. There is a further question, however, regarding the firm's responsiveness, defined as the ability to react to changes (Guiso, 1998). Will increased routinization lead to a more lethargic response or increased responsiveness?

As indicated above, routines increase the potential for focused attention (Simon 1947; Postrel \& Rumelt 1992; Walsh \& Ungson, 1991) by preserving scarce information-processing and decision-making capacity (Ashmos, Duchon \& McDaniel, 1998). Attention is usually focused on non-routine events whereas recurring events are dealt with semi-consciously (Cohen, 1991: 135; Postrel \& Rumelt 1992; Simon, 1947: 99). Since the semi-conscious processing of repetitive events requires less or almost no cognitive resources, this procedure, when established, leads to an increase in the available cognitive potential that may be used to attend to non-routine events. More precisely, after some periods of learning in which attention is directed at some activity, there is a tendency for habituation and smooth semi-conscious execution to substitute for attention (Reason, 1990).

In the case of change, events are always novel in some sense, and thus require nonroutine response. As aforementioned, responsiveness can be defined as the ability to react to changes. Since routinization, according to the above argument, increases the potential for focused attention, responsiveness should increase in routinization. Put differently, routinization introduces a division of labor where trivial frequently occurring events, such as straight rebuy in Webster \& Wind's influential classification of industrial buyer behavior, are handled with very limited resources. The resources, which would otherwise be employed in the absence of routinized behavior, are then free to respond to novel and changing events.

Hypothesis 4. Increasing routinization leads to an increase in responsiveness. 


\section{Detecting changes and responsiveness}

In the previous section, we argued that routinization would increase the firm's responsiveness. According to a literature survey of the strategy literature as well as related literatures, it appears that the notion of responsiveness consists mainly of three aspects (ABI Inform database 1996 to 1999): (1) reacting to changes, which can be broken down into the willingness and the readiness to do so (Guiso 1998), (2) reaction speed (Zaheer \& Zaheer, 1997), e.g. in the form of average production lead time and average work-in-processinventory, or cycle time, and (3) responsiveness to local signals, as opposed to global integration (Taggart, 1997). Because reacting to changes and reaction speed are directly related to the speed of detecting changes, there should be a positive correlation between detecting changes and responsiveness. This hypothesis builds on the assumption that the firm has the necessary free resources available to respond to change once it is detected. That is, we expect that intelligence dissemination will increase routinization (Hypothesis 3) and that routinization, in turn, will increase (the potential for) responsiveness (Hypothesis 4). Thus, given Hypotheses 3 and 4, we hypothesize:

Hypothesis 5. Increasing the speed of detecting changes increases responsiveness.

\section{Intelligence dissemination, uncertainty and the detection of changes}

In a very straightforward manner, information is a necessary prerequisite for detecting changes. Without information, one cannot get an impression of the state of the world, which then can be compared against the state of the world at a later point in time. In consequence, the correlation between intelligence dissemination and the detection of changes should be positive.

Hypothesis 6. Increasing intelligence dissemination leads to faster detection of changes. 
Finally, we believe that increasing uncertainty will decrease the firm's responsiveness. When uncertainty increases, workers and managers will be occupied with reducing uncertainty or simply be in a state of confusion where nobody knows what to do. Therefore, we hypothesize:

Hypothesis 7. Increasing uncertainty leads to a decrease in responsiveness.

In testing the above hypotheses, it must be noted that considering the role of culture in causing uncertainty and routinization is outside the scope of the present article and therefore a question for further research. As has been pointed out, the response of individual decisionmakers to uncertainty and other strategic issues is also influenced by national culture, as well as other factors (Schneider and De Meyer, 1991). This raises the point that there are different causes for uncertainty, and that additional strategies of responding to uncertainty (apart from routinization) might be thought of. However, we have defined the concepts of uncertainty and routinization in general terms independent of their specific underlying causes (including particular cultural influences). Also the constructs we use to capture aspects of information processing (intelligence dissemination and detecting change) have proven reliable across cultural settings (Jaworski and Kohli, 1996). We therefore expect that future research on the influences of culture on uncertainty and routinization will add important detail to our findings but not reject their general validity.

\section{METHODS}

\section{Data and Measures}

Data. The empirical test uses data from a survey on selected Danish industries conducted in 1999. The industries were chosen according to the criterion that they should experience different levels of uncertainty and all be subject to problems of information extensiveness. Since these characteristics are often associated with issues related to the natural 
environment in terms of conflicting demands from various different stakeholders (reducing environmental impact according to industry-, local-, regional-, national- and international standards etc.), we chose six industries with these characteristics. The selected industries were the chemical-, medical-, paint-, electronics-, textile- and dairy-industry. In operational terms, the industries were identified on the basis of the firm's NACE code for 1999 as registered in the publicly available database CD-Direct. A limit of employees $>10$ was used as cut-off point.

Using these criteria resulted in a sampling frame of 1007 firms with more than ten employees. An initial contact procedure was applied in order to increase the response rate and to record information that allowed a screening of firms not belonging to the sampling frame according to the above definition of the target population. According to the initial screening procedure (telephone interview), the sampling frame was adjusted to 908 firms. Out of these, 545 firms accepted to participate in the survey and were mailed a self-administered questionnaire to be returned by surface mail. Non-respondents were subsequently contacted by telephone in order to inspire response or, alternatively, elucidate a reason for non-response. The 545 firms accepting participation were divided into two groups: group 1 comprising 146 large or medium-sized firms with 50 or more employees, and, group 2 comprising 399 small firms with less than 50 employees.

The large or medium-sized firms were mailed two questionnaires: (1) a questionnaire (referred to as type A) directed to the firm's CEO, asking for detailed information at the strategic level, and (2) a questionnaire (referred to as type B) directed to the firm's environmental manager (or the person with equivalent responsibility), asking for detailed information regarding the firm's environmental practices. The small firms were only mailed one questionnaire (referred to as type C), directed to the firm's CEO, comprising a reduced form of the combination of questionnaires A and B. 
A total of 280 out of 908 firms returned at least one completed questionnaire to yield an overall response rate of $30.8 \%$ (27.0\% if we adjust for the influence of 2 questionnaires on the response rate). In view of the rather large material, which had to be completed, and the relatively modest interest in the content of the survey on part of at least some firms in the sample frame, this result seems reasonable.

Measures. Multiple-item composite scales measured all the constructs in order to increase reliability. Three types of scales were used in the survey. If possible, existing scales, which had a proven good track record in terms of reliability, were used. Thus Kohli, Jaworski \& Kumar's (1993) scale was used to measure the three constructs, intelligence dissemination, detecting change and responsiveness. It should be noted here that "detecting change" is a scale, which uses a subset of two items of Kohli et al.'s (1993) construct “intelligence generation." The two items measure the speed in discovery of demand-side and industry-wide changes. The constructs "intelligence dissemination" and "responsiveness" were adopted in unaltered form from Kohli et al. The reason the two items comprising the scale "detecting change" were used is that Kohli et al.'s original construct "intelligence generation" was not reliable. By contrast, as can be seen in Table 1, below, the other two constructs, as well as the modified construct "detecting change," had values of Cronbach's Alpha between 0.81 and 0.87 , which must be considered satisfactory.

\section{Table 1}

In the case of uncertainty (related to environmental issues), we adopted a two-item scale developed by one of the authors in a previous study and, on the basis of literature studies, added three possible items. The computed value of 0.73 for Cronbach's Alpha indicates a sufficient degree of scale-reliability. In fact, since the two-item scale from which it was developed had a Cronbach's Alpha of 0.60, this represents significant improvement. 
The routines-scale was developed anew on the basis of theoretical considerations. The five selected items capture routinization as frequent social interaction (use of task groups), frequent use of fixed goals (for cost control) and frequent comparative cost analysis. The computed value of 0.74 for Cronbach's Alpha indicates a sufficiently high scale-reliability and thus suggests that this scale is a useful basis from which a routinization scale can be further developed.

We further employed a series of principal components analyses in order to test for unidimensionality. Since only one component had an eigenvalue above one, the scales are sufficiently unidimensional. We then assessed discriminant validity by testing the hypotheses that the correlation coefficients for any of the possible pairwise combinations of all five constructs did not deviate from unity. Since this hypothesis was rejected in all ten tests, we obtained sufficient discriminant validity.

Since new employees are likely to cause a temporary increase in routinization and uncertainty and perhaps have less ability to detect important changes, we included a control measuring the number of new managers hired. For comparable reasons, we also controlled for the number of "old" managers leaving. The effect of managers leaving can be positive if they are low performers or in any other way pose a problem. It can however also be negative if the organization looses valuable competence. Even if the effect of old managers leaving is not entirely clear, it is important to control for.

\section{Empirical Test of the Hypothesized Model}

We use structural equation modeling employing a series of nested models as suggested by Anderson \& Gerbing (1988). As shown in Table 2 below, six models were estimated: (1) the independence model (null structural model), (2), the next most likely constrained model, (3) the most likely constrained model, (4) the target model excluding controls (5) the most 
likely unconstrained model including controls, (6) the next most likely unconstrained model including controls.

We employ sequential chi-square difference tests under the null hypothesis of no significant difference between two nested structural models (see Steiger, Shapiro \& Browne, 1985). In addition to assessment of overall model fit by sequential chi-square difference tests, we used three incremental fit indices, Bentler's (1990) comparative fit index (CFI), the Tucker \& Lewis (1973) index (TLI) and Bollen's (1986) relative fit index. These three indices were employed since they are all corrected for degrees of freedom, an important requirement for the test of nested models. The CFI has been suggested as the most promising relative fit index (in the sense that it overcomes sample size dependence) but neglects the relative parsimony of alternative models. We, therefore supplement by the TLI, which puts a premium on parsimony.

Table 2 about here

We used maximum likelihood estimation and subsequently evaluated the fit of the models. Table 2 presents a summary of the results. To identify model 1 and $1^{*}$, we fixed the weights of seven error terms to unity. The difference between model 1 and model $1^{*}$ is that the latter assumes identical variance over the three constructs: intelligence dissemination, uncertainty and detection of change. As the model comparison in Table 3 below shows, there is no significant difference in fit between the more parsimonious model $1^{*}$ and model 1 . Neither do we see great differences in the fit indices. Both models provide excellent fit.

Comparing model $1 *$ and $2 *$ shows that the controls, "new mangers hired" and "old managers leaving" play a significant role in explaining routinization and detection of change. When looking at the effects of these control variables, it is comforting that they are positive and significantly correlated. That is, new managers tend to be hired as old ones are leaving. 
Moreover, when new managers are hired, uncertainty increases, routinization decreases and detection of change decreases. All effects seem intuitively plausible. That old managers leaving has the exactly opposite effect, is interesting since it may be viewed as the positive effect of getting rid of a problematic situation. Thus, uncertainty decreases, routinization increases and detection of change increases as old managers leave. Note, however, that only the routinization effect of old managers leaving is significant (at $\mathrm{p}=0.05$ ).

Table 3 about here

We next turn to the target model $(2 *)$ and the test of hypotheses. First note that the fit indices in Table 2 shows an excellent fit for model $2 *$. Then note that the model comparison shown in Table 3 below does not show any significant difference in fit between our target model $2^{*}$ and model $1 *$. Both models fit the data equally well.

Further note that there is no support for Hypothesis 7. Although the sign is as hypothesized, the effect is not significant. Strictly speaking, neither can Hypothesis 1 be supported at $\mathrm{P}=0.05$. At $\mathrm{P}=0.10$, however, the effect is significant and the positive sign supports Hypothesis 1. Finally, all the remaining effects are significant and have the expected sign. That is, our results support Hypotheses 2, 3, 4, 5, and Hypothesis 6 whereas Hypotheses 1 and 7 are rejected.

According to Kohli et al. (1993), the two constructs "intelligence dissemination" and "responsiveness" should be positively correlated. As can be seen from Table 3, this is indeed the case. As an additional piece of information, it should be noted that the path that controls for the possible influence of "detecting change" on "routinization" is not significant. Moreover, we included a covariance term to control for the interaction between "detecting change" and "uncertainty." As can be seen from the correlation shown in Table 3, there is a significant negative interaction between these two constructs. 
Next, we examined the more parsimonious models $3^{*}$ and $4 *$. As Table 3 shows, it cannot be rejected that they fit the data equally well as models 1 and $1 *$. What happens though is that the explanatory power decreases dramatically and the fit indices for model $4^{*}$ are clearly poorer than those estimated for the previous models. Since the estimated effects however remain remarkably stable across the five models, we may invest some confidence in the validity of the results.

\section{RESULTS}

We believe that the most important result is that Hypothesis 2, Heiner's hypothesis, was supported: increasing routinization will decrease uncertainty. To our knowledge, this is the first time Heiner's hypothesis has been put to an empirical test, and as indicated in the conclusion, this empirical finding may have significant theoretical implications.

Also Hypothesis 3 was supported: increasing intelligence dissemination leads to an increase in routinization. This indicates that routinization may help free up cognitive resources and therefore serve as a viable strategy to overcome problems associated with cognitive limitations. The hypothesis that increasing routinization not only frees up limited cognitive resources, but also does this in a way that responsiveness is increased (Hypothesis 4) was supported. We believe a plausible explanation for this finding is that frequently occurring events are dealt with semi-consciously, while cognitive resources (attention for example) are responding to novel and changing events. Hypothesis 5, that increasing the speed of detecting changes increases responsiveness, was supported as well. This is consistent with the support for Hypotheses 3 and 4. Finally, there was support for Hypothesis 6, that increasing intelligence dissemination leads to faster detection of changes, which also adds consistency to our system of hypotheses: without information, it is impossible to compare the old and the new, and thus impossible to detect changes. 
While Hypothesis 2-6 were supported, Hypotheses 1 and 7 were rejected. Even though the estimate has the right sign, and is significant at $\mathrm{p}=0.10$, Hypothesis 1 must be rejected. So, increasing intelligence dissemination in an information extensive world does not necessarily increase uncertainty. It seems important to better understand the reason for this result. One possibility is simply that our measures were too coarse. In addition, "information extensiveness" was an alleged attribute of the environment of the firms included in our survey. A future study may consider an alternative research design in which an explicit measure of "information extensiveness" is included. A second and altogether different reason for the rejection of Hypothesis 1 may be that information will only influence uncertainty if the received information entails a binding commitment to act. Otherwise, the information may simply be ignored. The second rejected hypothesis was Hypothesis 7. Although showing the right sign, the effect is not significant. So we cannot conclude that increasing uncertainty leads to a decrease in responsiveness.

\section{DISCUSSION AND CONCLUSIONS}

The present article has proposed and tested a descriptive model that indicates how routines allow managers to successfully cope with pervasive uncertainty. The results have a number of implications:

First, our empirical results are consistent with the theoretical argument, that routines help managers cope with Knightean uncertainty. If this is true, it is problematic to assume that Knightean uncertainty can always be reduced to risk as suggested by standard approaches to the theory of choice. From a theoretical viewpoint, this reduction of Knightean uncertainty will cause an unfortunate blind spot. The empirical results suggest that it is important to distinguish between pervasive, "Knightean" uncertainty and weaker forms of uncertainty. The implication for theory is the need to conceptually distinguish between the two forms of uncertainty. As has been shown, confounding the two types of uncertainty and choosing to 
increase the information available in both cases might decrease performance in managerial decision-making under uncertainty.

Second, the empirical results support what Simon as well as Cyert \& March (1963) have long stated: limited attention plays a crucial role in deciding the feasibility of decision- and problem-solving strategies. When attention is the scarce resource, strategies that do not require much of it are at a premium. Interestingly, although the message has been around since the 1950 's, it is now gaining new momentum due to the rapid and massive changes in the economy caused by the Internet. In the wake of this, one of the leading books on the Network Economy talks about the "Economics of Attention" (Shapiro \& Varian 1999: 6) - a resurrection of March and Olsen's (1976: 22) call for a "Theory of Organizational Attention." The arguments of the present paper - supported by the empirical analysis -is a further reason to set the inquiry into mechanisms of allocation of individual and organizational attention high on the research agenda.

Third, the results are consistent with the idea that managers seek to cope with problems of limited attention by strategies that free cognitive resources. Fixing the recurring and relatively unimportant parameters in a decision problem by habitualization and routinization seems to be amongst the more common of such strategies. Although our empirical analyses are limited in scope, we believe that there is a whole range of semi-conscious mechanisms dealing with recurring problems so attention can be freed to focus on novel problems. Even though such mechanisms have been studied in the theory of human error (Reason, 1990), they tend to be ignored in both economic and managerial theories of choice. We believe that identification of these semi-conscious mechanisms, and to understand the interaction between a semi-automatic mode of operation and a knowledge-based mode of operation deserve much more attention in economic and managerial theories of choice. The terms 'habit' and 'routines' might be a good starting point for exploring this avenue. 
Fourth, the strong support for Hypothesis 2 as well as the consistency of this result with the support for Hypotheses 3-6 imply that habitualization and routinization must be viewed as general uncertainty decreasing strategies. Habits and routines are fundamental and commonly used mechanisms for dealing with choice in the face of pervasive uncertainty. Not only is the theoretical importance of pervasive uncertainty increasingly acknowledged, also a wealth of management texts indicate that various sources of pervasive uncertainty are becoming more and more virulent in recent times. For these reasons, re-directing attention to routinization as a key strategy in coping with pervasive uncertainty should be high on the agenda of economic and managerial theories of choice. 


\section{REFERENCES}

Anderson, J.C. \& D. W. Gerbing 1988. Structural equation modelling in practice: A review and recommended two-step approach, Psychological Bulletin, 103: 411-423.

Ashmos, D., Duchon, D. \& McDaniel R. 1998. Participation in strategic decision-making: The role of organizational predisposition and issue interpretation. Decision Sciences, 29(1): 25-51.

Bentler, P.M. 1990. Comparative fit indexes in structural models. Psychological Bulletin, 107: $238-246$.

Bollen, K. A. 1986. Sample size and Bentler and Bonnett's nonnormed fit index, Psychometrika, 51: 375-377.

Cohen, M. 1991. Individual learning and organizational routine: Emerging connections. Organization Science, 2(1): 135-139.

Cyert, R. M. \& March, J. G. 1992. A behavioral theory of the firm (2 $2^{\text {nd }}$ ed.). Oxford: Blackwell.

Egidi, M. \& Ricotilli, M. 1997. Coordination and specialization. Trento: Papers/ University of Trento, Computable and Experimental Economics Laboratory (Working Paper, RePEc:wop:uteepu:9703).

Guiso, L. 1998. High-tech firms and credit rationing. Journal of Economic Behavior and Organization, 35(1): 39-59.

Heiner, R. 1983. The origin of predictable behavior. American Economic Review, Vol. 73, No. 4, 560-595. Reprinted in Hodgson, G. M. (Ed.). The economics of institutions: 330365. Aldershot: Edward Elgar.

Hodgson, G. M. 1988. Economics and institutions. Oxford: Polity Press.

Kagel, J.K. and Roth, A.E. 1995. Handbook of experimental economics. Princeton: Princeton University Press. 
Jaworski, B. J. and A. K. Kohli, (1996), Market Orientation: Review, refinement, and roadmap, Journal of Market Focused Management, 1, 119-35.

Keynes, J. M. 1973. The general theory and after, Part II: Defence and development. Collected writings of John Maynard Keynes, Vol. 4. London: Macmillan.

Knight, F. 1921. Risk, uncertainty and profit. Boston: Houghton.

Knight, F. \& Merriam, T.W. 1948. The economic order and religion. Kegan Paul, London.

Kohli, A. K., Jaworski, B. J., \& Kumar, A. 1993. MARKOR: A measure of market orientation. Journal of Marketing Research, 30: 467-477.

Loasby, B. J. 1999. Knowledge, institutions and evolution in economics. Routledge, London.

Luce, R.D. \& Raiffa, H. 1957. Games and decisions. New York: Wiley.

March, J.G. 1978. Bounded rationality, ambiguity, and the engineering of choice. The Bell Journal of Economics, 9 (2): 587-614

March, J. G. \& Olsen, J. P. 1976. Ambiguity and choice in organizations. Oslo: Universitetsforlaget.

March, J. G. \& Simon, H. A. 1958/1993. Organizations. Oxford: Blackwell.

Nelson, R.R. \& Winter, S.G. 1982. An evolutionary theory of economic change. Cambridge: Harvard University Press.

North, D.C. 1990. Institutions, institutional change and economic performance. Cambridge: Cambridge University Press.

Perrow, C. 1970. Organizational analysis: A Sociological view. Belmont, CA: Wadsworth.

Postrel, S. \& Rumelt, R. (1992): Incentives, routines and self-command. Industrial and Corporate Change, 1(2): 397-425.

Radner, R. 1994. Uncertainty and general equilibrium. In Eatwell, J., Milgate, M., Newman, and P. (Eds.). The new Palgrave of economics, Vol. 4: 734-741. London: Macmillan.

Reason, J. 1990. Human error. Cambridge: Cambridge University Press. 
Richardson, G.B. 1960. Information and investment - A study in the working of the competitive economy. Oxford: Oxford University Press.

Runde, J. 1998. Clarifying Frank Knight's discussion of the meaning of risk and uncertainty. Cambridge Journal of Economics, 22: 539-546.

Savage, L.J. 1954. The foundations of statistics. New York: Dover Publications, Inc.

Schneider, Susan C. and De Meyer, Arnoud 1991. Interpreting and responding to strategic issues: the impact of national cultures. Strategic Management Journal, 12: 307-320.

Shapiro, C. \& Varian, H. 1999. Information rules. A strategic guide to the network economy. Boston, MA: Harvard Business School Press.

Simon, H. A. 1947/ 1997. Administrative behavior (4 ${ }^{\text {th }}$ ed.). New York: The Free Press.

Simon, H. A. 1955. A behavioral model of rational choice. Quarterly Journal of Economics, 69: 99-118.

Steiger, J. H., A. Shapiro \& M. W. Browne 1985. On the multivariate asymptotic distribution of sequential chi-square statistics, Psychometrika, 50: 253-264.

Taggart, J. H. 1997. An evaluation of the integration-responsiveness framework: MNC manufacturing subsidiaries in the UK. Management International Review, 37(4): 295318.

Tucker, L. R. \& C. Lewis 1973 . The reliability coefficient for maximum likelihood factor analysis, Psychometrika, 38: 1-10.

Walsh, J. P. \& Ungson, G. R. 1991. Organizational memory. Academy of Management Review, 16(1): 57-91

Weick, K. E. 1995. Sensemaking in organizations. Thousand Oaks: Sage.

Zaheer, A. \& Zaheer, S. 1997. Catching the wave: Alertness, responsiveness, and market influence in global electronic networks. Management Science, 43(11): 1493-1509. 
TABLES AND FIGURES

TABLE 1

Descriptives and coefficient Alpha for scales

\begin{tabular}{|c|c|c|c|c|c|}
\hline & $\mathbf{N}$ & Mean & Std. Dev. & Skewness & Kurtosis \\
\hline \multicolumn{6}{|c|}{ Intelligence dissemination ${ }^{\mathrm{a}}, 5$ items, Cronbach's Alpha $=0.87$} \\
\hline interdepartmental meetings & 56 & 5.20 & 1.95 & -1.04 & -0.15 \\
\hline $\begin{array}{l}\text { spend time discussing } \\
\text { between departments }\end{array}$ & 56 & 5.36 & 1.69 & -1.22 & 0.77 \\
\hline $\begin{array}{l}\text { everyone informed in short } \\
\text { time }\end{array}$ & 56 & 5.39 & 1.56 & -0.96 & 0.29 \\
\hline regular dissemination & 56 & 4.23 & 1.82 & -0.11 & -1.16 \\
\hline fast to notice others & 61 & 5.49 & 1.83 & -0.21 & 0.08 \\
\hline Scale & 56 & 5.07 & 1.33 & & \\
\hline \multicolumn{6}{|c|}{ Routinization $^{c}, 5$ items. Cronbach's Alpha $=0.74$} \\
\hline $\begin{array}{l}\text { frequency of use of task } \\
\text { groups in preparing strategic } \\
\text { decisions }\end{array}$ & 56 & 5.02 & 1.55 & -1.11 & 0.92 \\
\hline $\begin{array}{l}\text { frequency of use of task } \\
\text { groups in development } \\
\text { schemes }\end{array}$ & 56 & 5.88 & 1.34 & -1.52 & 2.52 \\
\hline $\begin{array}{l}\text { frequency of use of fixed } \\
\text { goals for controlling costs }\end{array}$ & 56 & 6.16 & 0.93 & -1.04 & 1.01 \\
\hline $\begin{array}{l}\text { frequency of use of fixed } \\
\text { goals for production costs }\end{array}$ & 56 & 5.61 & 1.51 & -1.17 & 0.88 \\
\hline $\begin{array}{l}\text { frequency of comparative } \\
\text { analysis of production cost } \\
\text { variations with regard to } \\
\text { goals }\end{array}$ & 56 & 5.86 & 1.45 & -1.80 & 3.06 \\
\hline Scale & 56 & 5.70 & 0.96 & & \\
\hline
\end{tabular}


TABLE 1, ctd.

Descriptives and coefficient Alpha for scales

Uncertainty $^{\mathrm{b}} .5$ items. Cronbach's Alpha $=0.73$

\begin{tabular}{lccccc}
\hline $\begin{array}{l}\text { Don't react because } \\
\text { uncertainty is so great: }\end{array}$ & 56 & 2.70 & 1.74 & 1.01 & 0.55 \\
$\begin{array}{l}\text { Uncertainty regarding how to } \\
\text { include environmental } \\
\text { regards into management: }\end{array}$ & 56 & 2.45 & 1.52 & 0.98 & 0.30 \\
$\begin{array}{l}\text { Uncertainty related to costs } \\
\text { induced }\end{array}$ & 56 & 4.27 & 1.95 & -0.04 & -1.10 \\
$\begin{array}{l}\text { Uncertainty as to how to } \\
\text { consider demands from } \\
\text { authorities }\end{array}$ & 56 & 3.64 & 1.83 & 0.48 & -0.57 \\
$\begin{array}{l}\text { Uncertainty as to how to } \\
\text { consider demands from other } \\
\text { externals }\end{array}$ & 56 & 3.30 & 1.65 & 0.55 & 0.07 \\
Scale & & & & & \\
\end{tabular}

Detecting change ${ }^{\mathrm{a}} .2$ items. Cronbach's Alpha $=0.87$

\begin{tabular}{|c|c|c|c|c|c|}
\hline $\begin{array}{l}\text { Fast to discover changes in } \\
\text { customer preferences }\end{array}$ & 61 & 5.66 & 1.63 & -0.06 & 0.26 \\
\hline $\begin{array}{l}\text { Fast to discover fundamental } \\
\text { changes in our trade }\end{array}$ & 61 & 5.98 & 1.60 & -0.56 & 0.89 \\
\hline Scale & 61 & 5.54 & 1.23 & & \\
\hline
\end{tabular}

Responsiveness '. 9 items. Cronbach's Alpha $=0.81$

\begin{tabular}{|c|c|c|c|c|c|}
\hline $\begin{array}{l}\text { Quick decision on reaction to } \\
\text { price changes }\end{array}$ & 61 & 5.67 & 1.86 & -0.51 & 0.30 \\
\hline $\begin{array}{l}\text { Tendency to perceive } \\
\text { changes in customer needs }\end{array}$ & 61 & 5.57 & 1.66 & 0.08 & 0.26 \\
\hline $\begin{array}{l}\text { Periodic review of product } \\
\text { development }\end{array}$ & 56 & 5.68 & 1.32 & -1.87 & 4.77 \\
\hline $\begin{array}{l}\text { Regular interdepartmental } \\
\text { meetings on reactions to } \\
\text { external changes }\end{array}$ & 56 & 4.98 & 1.69 & -0.67 & 0.00 \\
\hline $\begin{array}{l}\text { Immediate implementation of } \\
\text { response to competitor } \\
\text { campaigns }\end{array}$ & 56 & 5.89 & 1.22 & -1.11 & 1.01 \\
\hline $\begin{array}{l}\text { Inter-departmental activities } \\
\text { well-coordinated }\end{array}$ & 56 & 5.14 & 1.24 & -0.81 & 1.04 \\
\hline $\begin{array}{l}\text { Customer complaints are } \\
\text { perceived }\end{array}$ & 61 & 6.43 & 1.56 & -1.56 & 3.96 \\
\hline $\begin{array}{l}\text { Manage to implement plans } \\
\text { in time }\end{array}$ & 61 & 5.46 & 2.04 & -0.43 & -0.31 \\
\hline $\begin{array}{l}\text { Involved departments } \\
\text { coordinate product changes }\end{array}$ & 56 & 5.77 & 0.97 & -0.62 & 0.05 \\
\hline Scale & 56 & 5.49 & 0.90 & & \\
\hline
\end{tabular}

Controls

\begin{tabular}{|c|c|c|c|c|c|}
\hline Old managers leaving & 56 & 1.68 & 1.65 & 1.41 & 1.87 \\
\hline New managers hired & 56 & 2.27 & 2.12 & 1.44 & 2.56 \\
\hline
\end{tabular}




\section{TABLE 2}

\section{Model estimation and goodness of fit statistics}

\begin{tabular}{|c|c|c|c|c|c|c|c|c|c|c|}
\hline \multirow[b]{2}{*}{ Path } & \multicolumn{2}{|c|}{ Model 1} & \multicolumn{2}{|c|}{ Model 1* } & \multicolumn{2}{|c|}{ Model 2* } & \multicolumn{2}{|c|}{ Model 3* } & \multicolumn{2}{|c|}{ Model 4* } \\
\hline & $\begin{array}{r}\text { Std. } \\
\text { Coeff. }\end{array}$ & $\mathbf{P}$ & $\begin{array}{r}\text { Std. } \\
\text { Coeff. }\end{array}$ & $\mathbf{P}$ & $\begin{array}{r}\text { Std. } \\
\text { Coeff. }\end{array}$ & $\mathbf{P}$ & $\begin{array}{r}\text { Std. } \\
\text { Coeff. }\end{array}$ & $\mathbf{P}$ & $\begin{array}{r}\text { Std. } \\
\text { Coeff. }\end{array}$ & $\mathbf{P}$ \\
\hline Intelligence dissemination ---> Routinization & 0.21 & 0.03 & 0.19 & 0.04 & 0.18 & 0.04 & 0.19 & 0.04 & 0.19 & 0.04 \\
\hline Intelligence dissemination ---> Uncertainty & 0.17 & 0.05 & 0.14 & 0.07 & 0.16 & 0.06 & 0.16 & 0.06 & 0.16 & 0.06 \\
\hline Intelligence dissemination ---> Detecting change & 0.20 & 0.03 & 0.18 & 0.04 & 0.16 & 0.05 & --- & --- & --- & --- \\
\hline Routinization ---> Uncertainty & -0.19 & 0.04 & -0.17 & 0.05 & -0.19 & 0.04 & -0.20 & 0.03 & -0.20 & 0.03 \\
\hline Routinization ---> Responsiveness & 0.14 & 0.03 & 0.14 & 0.03 & 0.14 & 0.03 & 0.15 & 0.04 & --- & --- \\
\hline Detecting change ---> Routinization & 0.02 & 0.22 & 0.02 & 0.22 & 0.06 & 0.16 & --- & --- & --- & --- \\
\hline Detecting change ---> Responsiveness & 0.25 & 0.00 & 0.27 & 0.00 & 0.26 & 0.00 & --- & --- & --- & --- \\
\hline Uncertainty ---> Responsiveness & -0.05 & 0.15 & -0.05 & 0.15 & -0.05 & 0.15 & -0.11 & 0.07 & --- & --- \\
\hline \multicolumn{11}{|l|}{ Controls } \\
\hline New managers hired ---> Uncertainty & 0.23 & 0.05 & 0.22 & 0.05 & --- & --- & --- & --- & --- & --- \\
\hline New managers hired ---> Routinization & -0.22 & 0.05 & -0.22 & 0.05 & --- & --- & --- & --- & --- & --- \\
\hline New managers hired ---> Detecting change & -0.35 & 0.01 & -0.34 & 0.01 & --- & --- & --- & --- & --- & --- \\
\hline Old managers leaving ---> Uncertainty & -0.12 & 0.12 & -0.11 & 0.13 & --- & --- & --- & --- & --- & --- \\
\hline Old managers leaving ---> Routinization & 0.30 & 0.02 & 0.31 & 0.02 & --- & --- & --- & --- & --- & --- \\
\hline Old managers leaving ---> Detecting change & 0.19 & 0.06 & 0.19 & 0.07 & --- & --- & --- & --- & --- & --- \\
\hline \multicolumn{11}{|l|}{ Correlations } \\
\hline Intelligence dissemination <---> Responsiveness & 0.71 & 0.00 & 0.68 & 0.00 & 0.69 & 0.00 & 0.69 & 0.00 & --- & --- \\
\hline Detecting change <---> Uncertainty & -0.17 & 0.05 & -0.27 & 0.04 & -0.34 & 0.02 & --- & --- & --- & --- \\
\hline New managers hired <---> Old managers leaving & 0.64 & 0.00 & 0.64 & 0.00 & --- & --- & --- & --- & --- & --- \\
\hline \multicolumn{11}{|l|}{ Goodness-of-Fit } \\
\hline D.f. & 4 & 0.93 & 6 & 0.89 & 2 & 0.62 & 1 & 0.35 & 1 & 0.35 \\
\hline Chisq & 0.89 & & 2.31 & & 0.96 & & 0.89 & & 0.89 & \\
\hline Cmin/d.f. & 0.22 & & 0.39 & & 0.48 & & 0.89 & & 0.89 & \\
\hline NFI. IFI. TLI. CFI & 0.99 & & 0.98 & & 0.98 & & 0.98 & & 0.85 & \\
\hline RMSEA & 0.00 & & 0.00 & & 0.00 & & 0.00 & & & \\
\hline \multicolumn{11}{|l|}{ Squared multiple correlations } \\
\hline Routinization & 0.10 & & 0.10 & & 0.04 & & 0.04 & & 0.04 & \\
\hline Uncertainty & 0.09 & & 0.08 & & 0.06 & & 0.05 & & 0.05 & \\
\hline Detection of change & 0.11 & & 0.10 & & 0.03 & & --- & & --- & \\
\hline Responsiveness & 0.19 & & 0.19 & & 0.19 & & 0.06 & & --- & \\
\hline
\end{tabular}

2-Tailed probabilities.

${ }^{\mathrm{a}}$ Model $1^{*}, 2^{*}, 3^{*}, 4^{*}$ : variance of intelligence disemination. uncertainty and detection of change constrained to identical values.

${ }^{\mathrm{b}}$ All Hoelter $0.05>200$, but RFI 0.90 for model 3* and 4*. 
TABLE 3

Model comparisons and incremental fit

\begin{tabular}{lrrr} 
Model & \multicolumn{3}{c}{ df Chi-Square Probability } \\
\hline Model 1 & 4 & 0.89 & 0.93 \\
Model 1* & 6 & 2.31 & 0.89 \\
Null model 1* & 21 & 98.31 & 0.00 \\
Model 2* & 2 & 0.96 & 0.62 \\
Null model 2* & 10 & 60.27 & 0.00 \\
Model 3* & 1 & 0.89 & 0.35 \\
Null model 3* & 6 & 48.52 & 0.00 \\
Model 4* & 1 & 0.89 & 0.35 \\
Null model 4* & 3 & 5.97 & 0.11 \\
& & & \\
Model comparison & & & \\
Model 1* against model 1 & 2 & 1.42 & 0.49 \\
Model 2* against model 1* & 4 & 1.36 & 0.85 \\
Model 3* against model 1* & 5 & 1.42 & 0.92 \\
Model 4* against model 1* & 5 & 1.42 & 0.92 \\
& & & \\
Model 1* against null model 1* & 15 & 96.00 & 0.00 \\
Model 2* against null model 2* & 8 & 59.31 & 0.00 \\
Model 3* against null model 3* & 5 & 47.63 & 0.00 \\
Model 4* against null model 4* & 2 & 5.08 & 0.08 \\
\hline
\end{tabular}


FIGURE 1

Conceptual model of proposed relations among constructs

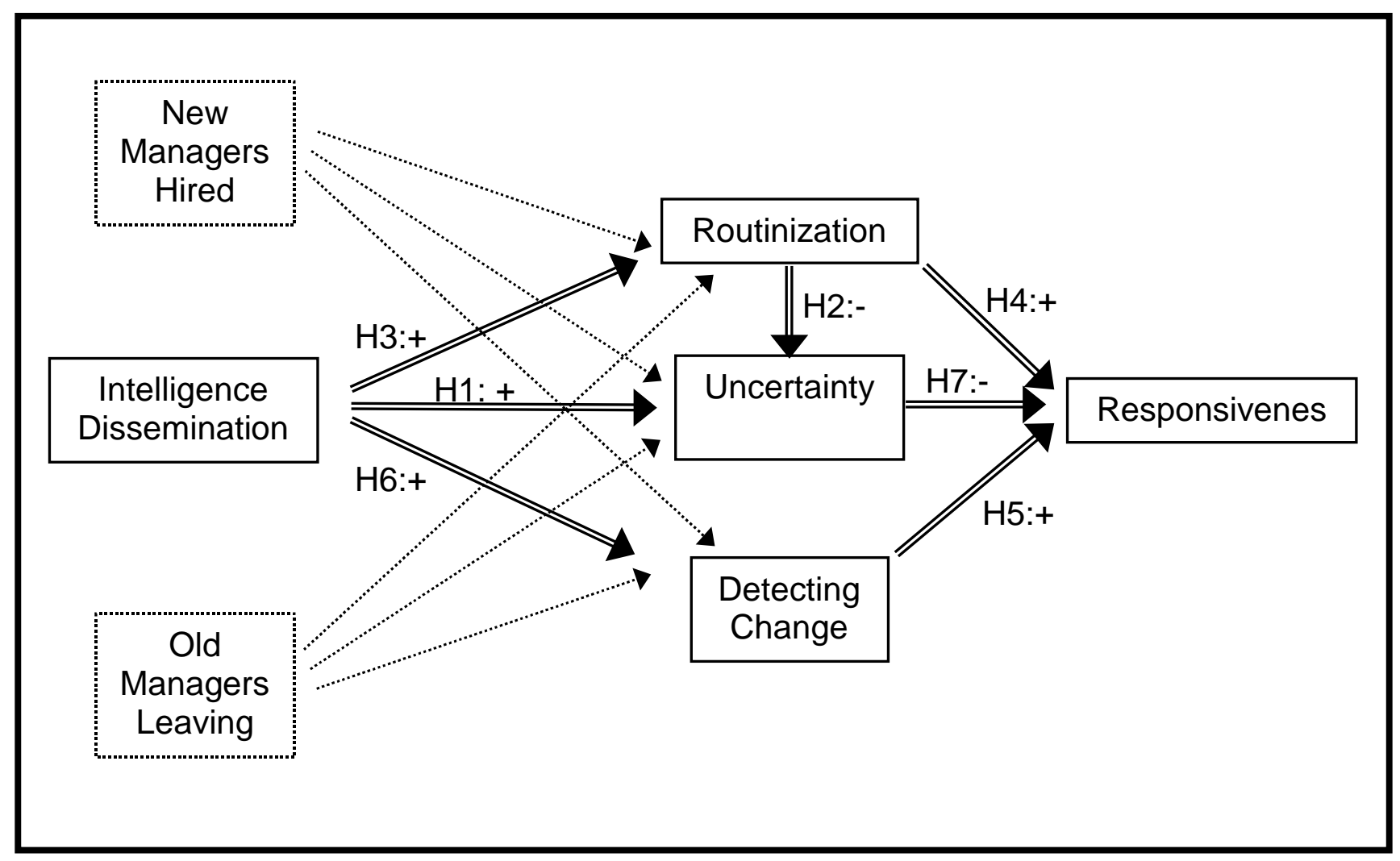

